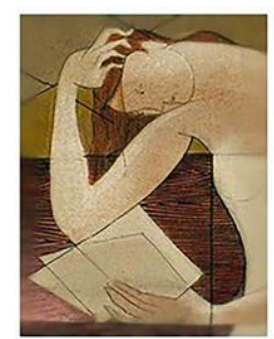

\title{
A escravidão brasileira e a servidão russa: aproximação entre dois sistemas sócio- econômicos através da narrativa curta em Machado de Assis e Ivan Turguêniev
}

\author{
Brazilian slavery and Russian serfdom: approximation between two socio- \\ economic systems through the short narrative in Machado de Assis and Ivan \\ Turgenev
}

\begin{abstract}
Juliano Bruni Pereira ${ }^{1}$
Resumo: O artigo investiga o tratamento literário conferido aos sistemas de exploração do trabalho escravo, no Brasil, e de servidão, na Rússia, em contos de Machado de Assis e Ivan Turguêniev. Utilizando a noção proposta por Moretti de "malformações nacionais", e de "periferia do capitalismo", proposta por Schwarz, que aproximam Brasil e Rússia no contexto dos desenvolvimentos políticos, sociais e econômicos nacionais em meados do século XIX, o trabalho procura estabelecer um raciocínio sobre o processamento literário desses dois regimes de produção enquanto formas de representação da realidade social brasileira e russa do tempo dos escritores.
\end{abstract}

Palavras-chave: Machado de Assis; Ivan Turguêniev; escravidão; servidão; Rússia.

Abstract: The article investigates the literary treatment given to systems of exploitation of slave labour, in Brazil, and serfdom, in Russia, in short stories by Machado de Assis and Ivan Turgenev. Using the notion proposed by Moretti of "national malformations", and of "periphery of capitalism" proposed by Schwarz, which brings Brazil and Russia together in the context of national political, social and economic developments in the mid-19th century, the work seeks to establish a reasoning about literary processing of these two production regimes as forms of representation of the Brazilian and Russian social reality of the time of the writers.

Keywords: Machado de Assis; Ivan Turgenev; slavery; serfdom; Russia.

Machado de Assis e Ivan Turguêniev foram escritores quase contemporâneos separados por grandes distâncias geográficas e culturais, mas aproximados pela existência social de suas nações no século XIX. Individualmente, diferenciavam-se pelos lugares que ocupavam na estrutura de suas sociedades: o brasileiro tinha origem humilde e insistiu na busca pessoal da própria educação e sofisticação intelectual, enquanto o russo podia contar com a estabilidade e a tranquilidade de uma vida abastada e protegida pelo status de nobre, com períodos de estudos na Europa ocidental e a participação direta e constante na classe letrada de seu país. Ambos têm a importância

\footnotetext{
${ }^{1}$ Mestrando em Letras da Universidade Federal do Rio Grande do Sul. Graduado em Jornalismo (2004) e História (2018) pela UFRGS.
} 
artística reconhecida e o estilo admirado. Turguêniev agiu enfaticamente, de seu lugar social, no que percebia como reformas necessárias ao desenvolvimento da Rússia. Machado codificou mais sua percepção da realidade coletiva, compondo obras em que as grandes questões sociais se imiscuíam, ao ponto do disfarce, em tramas psicologizadas. Ainda assim, o brasileiro se oferece como exímio indicador das condições de vida de sua época e local, o Rio de Janeiro do século XIX, microcosmo muito específico de um momento definidor da história moderna. Turguêniev, por sua vez, é parte indispensável para a compreensão da história russa do mesmo período e além. Suas obras exerceram influência direta na construção de uma opinião pública, na proposição, análise e circulação de ideias candentes, ao mesmo tempo em que funcionavam como termômetro do debate social e influenciavam nele.

Este trabalho volta sua atenção aos dois escritores a partir das perspectivas que eles oferecem à compreensão histórica de suas sociedades. Especificamente, o artigo procura aproximá-los através da noção de que tanto Machado quanto Turguêniev representam expressões culturais (e, portanto, sociais) da periferia do capitalismo no seu momento de maior expansão e força de inserção avassaladora (pacífica ou violenta) no contexto mundial. A fim de explorar — ainda que de forma bastante incipiente e parcial - a potencial conexão entre suas obras e a realidade social em que viveram e escreveram, proponho a análise de dois contos, colocados em paralelo a partir do critério de que representam forças sociais exemplares de seus contextos nacionais, periféricos em relação ao centro cultural capitalista. Interessa sobretudo extrair uma amostra (contida de maneira concentrada na narrativa curta) da abordagem literária que Machado e Turguêniev deram aos sistemas sócio-econômicos de suas nações. Aproximar Machado e Turguêniev, penso, significa examinar equivalências a título de investigação não apenas literária, mas também histórica. O escravagismo brasileiro e o regime de servidão russo podem ser vislumbrados em suas obras e manifestam características próprias das sociedades colocadas na periferia do capitalismo durante o século XIX. Com isso em mente, esse trabalho analisa em paralelo os contos Pai contra mãe, do escritor brasileiro, e Khor e Kalínitch ${ }^{2}$, do autor russo, destacando os elementos centrais nos textos no que se refere aos estatutos sociais próprios dos sistemas escravista e servil.

\footnotetext{
2 Todas as referências aos contos serão feitas a partir de ASSIS, Machado de. 50 contos de Machado de Assis. Seleção, introdução e notas por John Gledson. São Paulo: Companhia das Letras, 2007. p. 466-475, e TURGUÊNIEV, Ivan. Memórias de um caçador. Tradução, posfácio e notas de Irineu Franco Perpetuo. São Paulo: Editora 34, 2017. p. 7-22.
} 


\section{Pai contra mãe: denúncia (extemporânea) da escravidão}

O conto Pai contra mãe, de Machado de Assis, aparece em 1906, integrando o último volume publicado em vida pelo escritor fluminense, Relíquias da casa velha. $\mathrm{O}$ texto abre o livro e é considerado a mais enfática abordagem de Machado em relação à escravidão (uma verdadeira e própria denúncia dessa instituição, segundo John Gledson $^{3}$ ). A narração acontece em terceira pessoa e inicia com o relato de usanças e características próprias do regime de escravidão. Logo na abertura, o narrador situa a escravidão já no passado, sendo o texto uma produção posterior à abolição formal da escravatura, em 1888. Os cinco primeiros parágrafos tecem considerações sobre utensílios utilizados no controle corporal e psicológico dos escravos, sobre as relações e comportamentos que se estabeleciam (como as fugas, os apadrinhamentos, a violência física) e as medidas de administração dos proprietários dos escravos (a recaptura dos fugidos e o mercado econômico secundário a que dá origem). É nesse último aspecto do "negócio escravidão" que irá se inserir a história de Cândido Neves, homem livre empobrecido (presumivelmente branco) que se dedica ao ofício de apanhador de escravos fugidos.

Antes de analisar o enredo do conto, parece necessário destacar a abertura de Pai contra mãe em seu caráter funcional em relação ao restante do texto. Diferentemente do que acontece em diversos outros contos machadianos, os primeiros parágrafos não introduzem a história propriamente dita (não apresentam personagens, nem estabelecem uma trama ficcional), mas, como dito antes, relatam e ponderam sobre aspectos objetivos da escravidão de maneira despersonalizada. "Os escravos fugiam com frequência", "nem todos gostavam da escravidão": descrição ampla de atitudes e sentimentos coletivos, dispersos no tempo e no espaço, recorrentes independentemente de personalidade individual. As primeiras linhas horrorizam, porque expõem a violência logo de partida através da descrição da máscara de metal usada para prevenir e punir "o vício de beber" dos escravos - como se a intenção do autor fosse exatamente a de causar estupor e impacto. O narrador ilude o leitor: ao término do parágrafo afirma não mais se deter naquela temática grotesca ("Mas não cuidemos de máscaras”), para, no entanto, retomar na sequência o tópico da violência, desta vez através da descrição do ferro ao pescoço. A progressão do texto até a introdução do enredo aborda o grotesco da

\footnotetext{
${ }^{3}$ GLEDSON, John. Sobre o autor. In: ASSIS, Machado de. 50 contos de Machado de Assis. Seleção, introdução e notas por John Gledson. São Paulo: Companhia das Letras, 2007. p. 485.
} 
ordem social representada pelos instrumentos de controle e "correção", bem como as relações idiossincráticas decorrentes da escravidão, nas quais não apenas a violência física fica demonstrada (condificada pela máscara e pelo ferro de pescoço), mas também o cinismo da sociedade que a pratica ("o mesmo dono não era mau”).

Minha proposição é a de que, mais uma vez, o conto machadiano opera um jogo de manipulação do leitor. Pai contra mãe abre como uma descrição (fazendo uso de recursos ilusórios, prometendo o que descumpre logo em seguida) do grotesco e da insensatez da escravidão, não oferecendo um enredo com personagens pessoalizados e suas ações, mas apresentando um panorama social a partir de seus elementos mais salientes, ou seja, o aspecto da violência e a contradição emocional de opressores e oprimidos. Os parágrafos iniciais funcionam então como uma introdução à história de Candinho, mas ainda aqui há um truque narrativo: se o início do conto ilumina o escravizado vítima da violência e da incoerência humana e social, o enredo vai acompanhar a história não de um escravo, mas de um membro do sistema de opressão, ainda que seja ele mesmo um oprimido (em outras bases, como procurarei destacar). Penso que a importância narrativa dos trechos iniciais do conto se localiza no fato de que o ponto de vista apresentado de início será invertido, e do alvo da violência corporal e moral escravagista (o escravo) se passa a um veículo dessa, o indivíduo servil do sistema (despossuído) e que é parte de sua aplicação. O quadro social se complexifica ainda mais na percepção de que a opressão lança mão de recursos advindos de contradições mais abrangentes. O desamparo dos escravos fugidos se choca com o desamparo de uma classe de empobrecidos livres que ganham a vida como instrumentos de opressão.

Cândido Neves (Candinho) não é, portanto, um escravo. O contraste com a abertura do conto se estabelece completamente no sexto parágrafo, quando o protagonista é identificado como um apanhador de escravos fugidos. O desamparo de que é vítima é de ordem sobretudo econômica. Aliado à sua índole pessoal (que o impele a atitudes despreocupadas ao ponto da inconsequência, como a de não se fixar em nenhum emprego por desinteresse e leviandade), o problema de sua existência social é a pressão que a falta de recursos exerce sobre a sua subsistência. Candinho conhece Clara, também de origem pobre, e juntos decidem formar uma família. Tia Mônica, único familiar de Clara e que é responsável por sua criação e aconselhamento, alerta para as dificuldades que a família certamente sofrerá como resultado da inconsequência de Candinho, mesmo assim o casal decide ter um filho. A vida dos três (o casal e Tia 
Mônica) se projeta muito restrita e atinge seu ponto mais baixo, quando são obrigados a deixar a casa humilde em que habitam por aluguel. O ofício de Candinho, de início com retorno financeiro minimamente satisfatório, passa a ser disputado por vários outros despossuídos livres, e a lógica capitalista da concorrência se mostra também como subproduto do sistema escravocrata, levando a uma escassez de trabalho ${ }^{4}$. A inconstância e total falta de estabilidade (de trabalho e de remuneração) leva Candinho ao desespero absoluto. Relutante desde o início em acatar a sugestão de Tia Mônica de entregar o filho recém-nascido à Roda dos Enjeitados para aliviar a pressão econômica sobre o núcleo familiar e garantir a sobrevivência do menino, ele acaba por ceder e, com sofrimento imenso, promete levar o bebê na noite seguinte. Cândido então intensifica, como último esforço, algumas buscas por fugitivos, mas em vão. No caminho à Roda para a entrega do bebê, o apanhador de escravos localiza, por golpe de sorte, uma escrava fugida, de nome Arminda, cujo valor da retribuição pela captura é o mais alto disponível, extremamente rentável. Candinho a controla e, numa cena dramática, no mesmo instante a conduz violentamente ao proprietário. Arminda, porém, revela que está grávida e que será severamente punida pelo dono, "que o senhor era muito mau". Esse fato não sensibiliza Candinho, e a narração em nenhum momento sugere a hesitação do personagem. Reduzida novamente à submissão, Arminda aborta seu filho tão logo é entregue ao seu proprietário. Candinho então retorna para casa com os cem mil-réis de gratificação e o filho poupado do abandono. Todo o episódio é naturalizado por Tia Mônica, que censura a escrava pela fuga e pelo aborto. O conto se encerra com a frase fria proferida por Candinho: "Nem todas as crianças vingam".

\section{Khor e Kalínitch: propaganda sutil e defesa de transformações}

O conto Khor e Kalínitch foi publicado inicialmente na influente revista $O$ Contemporâneo (Современник, Sovremiênik) e posteriormente reunido a outros contos de Ivan Turguêniev em livro de 1852. A obra obteve um sucesso imediato, mas rendeu

\footnotetext{
${ }^{4}$ A trama do conto reflete, nas dificuldades financeiras de Candinho, uma provável cadeia de causa e efeito histórica. O enredo se passa "há meio século", portanto em meados do século XIX, considerando a data de publicação do conto. Em 1850 foi aprovada a lei Eusébio de Queirós, que criminalizou o comércio transatlântico de pessoas escravizadas. A consequência do súbito estancamento na oferta de mão-de-obra foi a elevação do preço dos escravizados e o aumento do tráfico interno. É também de se supor, com relativa segurança, que a propriedade de escravos (não ameaçada por aquela lei e que continuou a existir) recebesse maior cuidado administrativo da parte dos grandes escravocratas. Assim, a recuperação de escravos fugidos tende a ter sofrido um incremento bastante significativo devido ao capital financeiro envolvido e à impossibilidade de reposição fácil. Candinho vive desse expediente e se ressente da crescente concorrência em seu ofício de apanhador de fugitivos ("Um dia os lucros entraram a escassear. (...) No próprio bairro havia mais de um competidor”).
} 
ao autor uma condenação pela censura czarista à prisão domiciliar por um curto período sob a alegação de ridicularizar a classe proprietária. De maneira hostil, a acusação contra Turguêniev perguntava:

\begin{abstract}
Que utilidade tem, por exemplo, mostrar ao nosso povo letrado (...) nossos odnodvórtsi e camponeses, que o autor tanto poetizou, como administradores, racionalistas, românticos, idealistas, gente entusiasmada e sonhadora (sabe Deus onde foi encontrálos!), que nossos camponeses são oprimidos, que os proprietários de terra, que o autor tanto achincalha, expondo-os como torpes, selvagens e extravagantes, comportam-se de forma indecente e ilegal, que o clero das aldeias rasteja diante dos proprietários de terras, que isprávniki e outras autoridades aceitam suborno e que, obviamente, quanto mais livres os camponeses forem, melhor? (... $)^{5}$
\end{abstract}

A condenação de Turguêniev expressa uma ferrenha defesa do status quo, e a figura central do debate é o camponês e seu estatuto social. Cabe registrar que, no sistema social russo de servidão, então em vigor, o nobre (senhor de terras) é o proprietário legal não apenas de áreas agrícolas e sua produção, florestas, animais, massas d'água e benfeitorias, mas detém o poder sobre as populações de camponeses (mujiques) que se assentam em aldeias dentro dessas áreas. O servo está condicionado à posse por um senhor e atrelado à terra. A submissão legal do mujique aos senhores de terra, nobres proprietários, teve fim com o Manifesto de Emancipação de 1861 assinado pelo czar Alexandre II, mas mesmo antes disso Turguêniev já havia liberado seus servos do pagamento do obrok, principal tributo cobrado em benefício dos senhores. Turguêniev se via e era visto como um progressista, defensor de uma abertura e aproximação ideológica com a Europa - no acirrado debate travado no seio da classe letrada russa, o escritor fazia parte dos ocidentalistas, em franca oposição aos eslavófilos, tradicionalistas reacionários que fundamentavam sua posição na especificidade cultural russa. As considerações de Turguêniev sobre as causas do atraso russo e suas ponderações acerca da forma de contornar as dificuldades históricas e sociais de sua nação se refletem em toda sua criação literária, considerada muito politizada e de grande qualidade estética.

Khor e Kalínitch inicia de maneira similar a Pai contra mãe. O primeiro parágrafo apresenta uma descrição das diferenças entre duas regiões russas vizinhas, sublinhando características da geografia, mas também da índole dos camponeses de cada local. Interessa ao autor a melhor compreensão possível do sistema de valores do simples camponês. O narrador - não especificado, mas lido como o próprio autor - é um caçador que percorre ambas as regiões e faz relatos e ponderações sobre o espaço

\footnotetext{
${ }^{5}$ Cit. em BERNARDINI, Aurora Fornoni. Aulas de literatura russa: de Púchkin a Gorestein. São Paulo: Kalinka, 2018. p. 59.
} 
físico, a organização social, os costumes e traços psicológicos das pessoas e comunidades que vai encontrando. Ao perambular por áreas rurais da província russa, o autor trava relações com senhores (seus iguais do ponto de vista social) e mujiques. A atmosfera em que se desenvolve a narrativa é amena: o narrador preza o ambiente e o convívio, sentindo-se muito à vontade entre os camponeses ("eles falavam comigo sem constrangimento") -, o que contraria o desprezo característico das classes proprietárias pelos seus subalternos. Há respeito e cordialidade, e uma aparente harmonia social perpassa o conto.

A descrição verídica, logo no início do texto, das províncias (com nomes e informações geográficas precisas) sugere que o autor relata eventos ficcionalizados com lastro na sua experiência pessoal (de primeira ou segunda mão). É bastante razoável pensar que aquilo que o autor conta, ele deseja que seja lido como fato realmente acontecido e que, portanto, tenha valor de testemunho. O relato de "experiências" e a utilização de pessoas reais como "fio condutor" para suas criações literárias ${ }^{6}$ com o objetivo de testemunhar em defesa de um ponto de vista é uma das linhas centrais da obra de Turguêniev. Assim, o conto parece carregar a pretensão de funcionar como depoimento e reflexão. Como pano de fundo, em questão está a moralidade e pertinência do sistema servil.

A "ação" da trama se resume a visitas e diálogos entre os personagens. O narrador é recebido pelo pequeno proprietário Polutíkin. Entre os dois fica subentendida uma relação de solidariedade de classe. O narrador, no entanto, se diverte em elencar os defeitos e fraquezas de seu anfitrião, o que desempenha a função de denúncia dos vícios da classe nobre, sobretudo a pretensão e a empáfia. O narrador é então apresentado ao primeiro camponês, Khor, um "mujique esperto" que detém um status especial: Khor, após negociação com o proprietário dono das terras e o compromisso de pagar um tributo estipulado pelo nobre, obtém permissão para habitar uma zona remota da propriedade, junto a um pântano em meio à floresta, e é dispensado do trabalho obrigatório. Ou seja, trabalha para si próprio, devendo apenas o imposto ao seu patrão — no sistema social russo de então, a posição de Khor equivale a uma semiliberdade. Khor se torna um mujique enriquecido e, mesmo instado pelo proprietário a comprar

\footnotetext{
${ }^{6}$ Um dos elementos de distinção da produção literária de Ivan Turguêniev é o posicionamento temporal das tramas em um contexto histórico factual, notadamente o tempo de vida do escritor - reforçando, assim, critérios de plausibilidade e verossimilhança. Da mesma forma, realçando os efeitos de verdade de suas criações literárias, Turguêniev afirmava sentir a necessidade de basear seus personagens em pessoas reais de sua convivência, "vendo-os diante de si" a fim de lhe servirem "como que de fio condutor" (BIANCHI, 2012).
} 
sua alforria, prefere manter o antigo vínculo: "Hoje eu conheço o patrão e conheço o tributo... O nosso patrão é bom. (...) Se Khor estivesse entre os livres (...) todo mundo que não tivesse barba [os funcionários públicos] seria maior do que Khor”. O mujique, portanto, encontrou seu lugar social dentro do próprio sistema servil, preferindo a comodidade da posição que conquistou à incerteza de ser jogado, com a liberdade, em meio a um mundo em rápida transformação, de urbanização acelerada e o fim das relações tradicionais. Como livre, Khor não desfrutaria da estabilidade de que goza, estando sob a "proteção" do regime de servidão. Além disso, Khor comercia manteiga e alcatrão. Tornou-se, digamos, um microcapitalista, retirando lucros de seu trabalho, ainda que condicionado pelo seu vínculo servil (por sua vontade). Esse mujique vive feliz, e seu núcleo familiar é composto de muitos filhos, saudáveis e respeitosos (o narrador lhe elogia os filhos: "Que bela gente você tem!”).

No entanto, Khor conserva vícios automaticamente associados à sua classe. "Por mais inteligente que fosse, também tinha suas superstições e preconceitos", o maior deles o desprezo (temperado de condescendência) pelas mulheres: "gente estúpida", "a mulher é uma trabalhadora (...), serva do homem”. Em sua produção literária, Turguêniev trabalhou magistralmente as figuras femininas como personalidades fortes e destemidas, muitas vezes mais conscientes, equilibradas e ativas que seus personagens masculinos. Logo, não causa espanto que o preconceito do mujique tenha impactado negativamente o autor.

A condição social sui generis de Khor está simbolizada nas botas que calça. O sistema de códigos da hierarquia social russa daquele momento prevê que apenas os proprietários calçam botas, cabendo aos mujiques o uso das simples alpargatas. $\mathrm{O}$ contraste do estatuto de "mujique esperto" e de camponês subordinado ficará explícito no contato que o narrador estabelece, logo em seguida, com outro mujique, Kalínitch. Esse tem as alpargatas como símbolo de simplicidade e até de conformidade. Está totalmente subjugado ao seu senhor e conta com seu apreço (é "zeloso e obsequioso", nas palavras de Polutíkin); todos os dias o acompanha à caça, negligenciando o cuidado de suas próprias terras. O imobilismo social de Kalínitch se deve ao seu servilismo, mas ele não é julgado por isso. Esse mujique se revela ao narrador como pessoa gentil, sensível, vivaz, atenta e diligente. Kalínitch é inteligente e muito interessado em aprender.

O paralelo entre os dois mujiques, amigos sinceros um do outro, é construído como uma oposição de caracteres. Khor é "prático (...), racionalista", enquanto 
Kalínitch "pertencia aos idealistas, românticos". O primeiro "compreendia" o seu senhor e vivia afastado, já o segundo "venerava seu amo" e morava na aldeia. Kalínitch, mais jovem, sabia ler, ao passo que Khor, mesmo se mostrando atilado e sagaz, era analfabeto. O narrador sublinha esse aspecto dos dois camponeses, parecendo querer destacar o fato de que a educação formal não garante caráter: "Conversando com Khor, ouvi pela primeira vez a fala simples e inteligente do mujique russo".

Na primeira visita que faz a Khor, o narrador pede permissão para pernoitar no celeiro do mujique. Esse episódio concentra grande carga simbólica de uma desejada harmonia social: ao solicitar a hospedagem improvisada do servo, o senhor abala a ordem social, colocando-se em condições materiais mais precárias que seu subalterno. Khor se esmera no cuidado com o senhor, providenciando lençol e travesseiro. As atitudes sinceras são convertidas em respeito mútuo.

O conto se estrutura entre a descrição do convívio do narrador com os dois mujiques durante alguns dias e suas considerações sobre o universo social e moral dos camponeses. No relato há a clara preferência do narrador por essa convivência entre os mujiques em comparação com a recepção que tem da parte de seu colega de classe, Polutíkin, e esse é o ponto central da história: a atitude moral do narrador perante os preconceitos de classe. O conto compõe uma série de outros textos similares, que formam as Memórias..., relatando as experiências do narrador como caçador e suas reflexões sobre diversas questões relacionadas a problemas sociais e filosóficos. $\mathrm{O}$ andamento da série não parece ser condicionado por "eventos" que o narrador deseja comunicar, não há uma trama complexa de ações e reações, nem grandes pontos de inflexão ou desfechos. Cada conto ilumina um aspecto particular da experiência, compondo um quadro amplo e variado da vida (individual e social) russa. Khor $e$ Kalínitch serve de introdução a esse largo conjunto de retratos, antecipando ao leitor o método de Turguêniev: a narração de episódios menores e considerações filosóficas sobre eles.

\section{Uma aproximação literária de sistemas sociais periféricos}

\footnotetext{
${ }^{7}$ Essa dicotomia de caracteres foi explorada intensamente por Turguêniev. Suas maiores obras exibiam nos personagens o embate entre o entusiasmo e o altruísmo quixotesco e o egoísmo e a reflexão paralisante hamletiana. "Turguêniev argumentava que tanto o homem de ação fanático (D. Quixote) quanto o 'homem supérfluo', paralisado pela indecisão (Hamlet), eram figuras simpáticas e igualmente trágicas, cada um representando certos valores humanos que transcendiam sua situação imediata." (FRANK 1992, p. 85).
} 
No que se refere às dinâmicas das narrativas, em Turguêniev nada de especial — em termos de "nós narrativos", de "peripécias" - parece acontecer". O relato intercala descrição de episódios corriqueiros e reflexão: trata-se da experiência pessoal do narrador, em que o importante é destacar os eventos que serviram para a ponderação mais ampla. Em Machado, a história de Candinho ilustra e personifica o raciocínio inicial sobre a violência, mas o faz acompanhando o opressor (que também é oprimido pelas contingências do sistema econômico). $\mathrm{O}$ vetor da violência comentada no início do conto é secundário na maior parte do texto: a escrava fugitiva (a personificação, na trama, do alvo da violência comentada inicialmente) é apenas o desfecho e solução dos problemas do opressor social (o escravizador branco), porém também colocado em situação de desespero. Em Pai contra mãe, temos um confronto de desamparados diferenciados racial e, claro, socialmente, mas ainda assim pressionados pelas exigências da subsistência. O estatuto social de livre garante a Candinho a solução de seu desespero através do desespero transferido ao socialmente subalterno. $\mathrm{O}$ drama humano do pai que encontra sua salvação no sacrifício da condição de mãe da escravizada se soma à opressão que ambos sofrem enquanto figuras sociais marginais. Pobre e desamparado, Candinho, enquanto indivíduo livre, pode obter a sua salvação pela via de poder contar com indivíduos de papéis sociais ainda mais inferiores.

A redenção de Candinho, em seu contexto, só é possível graças à violência intrínseca ao sistema social brasileiro erigido sobre a escravidão. Machado de Assis, ao abrir o conto com recordações (não do protagonista, mas coletivas e impessoais, codificadas através do narrador) dos tempos da escravidão, traz para o primeiro plano o principal aspecto do sistema que é a violência e a arbitrariedade. Daí a ênfase, nos primeiros parágrafos, no grotesco e no cruel. Turguêniev aposta na direção contrária, acusando a estagnação russa a partir de seu sistema imóvel e preconceituoso. Certo que, como gentiluomo, apreciava os acordos e o respeito aos contratos sociais, a afabilidade no trato entre classes distintas no sistema de servidão. Mas sobretudo questionava o lugar social histórico do camponês russo perante um quadro geral em flagrante movimento. Dessa forma, os traços gerais positivos do mujique servem como apresentação de garantias que o escritor fornece aos seus pares de classe no sentido de defender a inserção da camada camponesa no mundo livre que via se desenvolver na

\footnotetext{
${ }^{8}$ Isso parece contradizer a ideia de Moretti (2014) de que no conto não há espaço (ou tempo) para os enchimentos, apenas para os nós. Em Turguêniev, a impressão geral é a de que essa dinâmica está invertida.
} 
Europa ocidental. Em Khor e Kalinitch, a cordialidade na relação entre servo e senhor tem o efeito (certamente deliberado) de propaganda, de tentativa de convencer os poderosos da necessidade de mudança através da exibição benévola e condescendente das virtudes dos subjugados.

Pai contra mãe e Khor e Kalínitch se prestam a uma interpreção histórico-social das sociedades que representam. O sistema de escravidão brasileiro e o servil russo se mostram não apenas economicamente incoerentes no momento apanhado pelas duas narrativas, mas já se encontram desgastados pelo, digamos, humanismo burguês que emerge das ruínas do Antigo Regime. É interessante, então, analisar essas criações literárias como pequenas amostras de realidades em transformação. O principal indicador do valor contido nesses dois contos, me parece, é o fato de que seus temas e objetos extrapolam o universo individual dos personagens, alojando-se no quadro social e histórico mais amplo. Os próprios autores propõem isso através de fórmulas abrangentes: "A escravidão levou consigo ofícios e aparelhos (...)", "Conversando com Khor, ouvi (...) a fala simples e inteligente do mujique russo" (grifos meus). As relações e os condicionamentos sociais e psicológicos dos narradores, de Candinho e de Khor e Kalínitch estão intimamente ligados à forma específica como suas sociedades estão organizadas. Como interessa ao olhar que lancei sobre os contos a noção de periferia do capitalismo no século XIX, procuro nesses escritos de Machado de Assis e Turguêniev reflexos de uma época e lugares sobre a imaginação literária. Brasil e Rússia aparecem como a quintessência da periferia daquele período. Não à toa Franco Moretti se utiliza dos estudos de Roberto Schwarz sobre Machado e busca na obra dos grandes mestres russos indícios do desenvolvimento capitalista novecentista9

Nesse sentido, proponho aqui um cruzamento de leituras de Pai contra mãe e Khor e Kalínitch, levando em consideração o lugar social de seus autores e a natureza de seus objetos. O primeiro aspecto que considero importante destacar é o momento de escrita dos contos. A publicação de Pai contra mãe acontece passadas quase duas décadas da abolição da escravatura no Brasil e funciona como uma memória renovada de uma questão sensível e central. Já Turguêniev compõe Khor e Kalínitch antes do fim do regime de servidão. Suas histórias são parte essencial da mudança, junto à opinião pública, da maneira como o sistema era visto e de como se enquadrava nos diferentes projetos de nação que estavam em disputa. A temporalidade da produção desses textos

\footnotetext{
9 MORETTI, Franco. O burguês: entre a história e a literatura. São Paulo: Três Estrelas, 2014. Particularmente o capítulo "Malformações nacionais": metamorfoses na semiperiferia, p. 150-173.
} 
em função de seus objetos altera, me parece, a compreensão dos contos. Machado inicia Pai contra mãe, resgatando pontualmente instrumentos e usos de coação e de violência, propondo ao leitor a recuperação (ou a informação) de uma série de condicionamentos sociais; Turguêniev demonstra, a passos muito lentos e sutis, a incoerência da subjugação de pessoas moral e socialmente capazes e complexas, buscando fazer do quadro que retrata um argumento de discurso social. Machado vai ao passado, ambienta sua história lá, mas o faz em função do presente. Turguêniev finca os pés no presente projetando um futuro, elaborando o que é a sua interpretação do que pode vir a ser.

A temporalidade da escrita influencia o tom dos textos. A atmosfera em que se desenvolvem as narrativas difere pelo fato de terem objetivos diversos. Turguêniev preza o ambiente e o convívio com as pessoas que servem de justificativa para o seu discurso, o que sugere que sua argumentação traz o intuito de convencer pela cadência na apresentação dos fatos: a inteligência e dinamismo dos mujiques, os vícios e limitações da classe dominante, as qualidades morais dos camponeses, a sugestão velada dos benefícios (econômicos, humanos e morais) que uma mudança de organização social pode proporcionar, a incoerência da subjugação. O narrador machadiano insinua um desconforto - que é moral - em relação à escravidão pelo uso de ironias e códigos complexos de contrariedade ("Eram muitos [os escravos], e nem todos gostavam da escravidão. Sucedia ocasionalmente apanharem pancada, e nem todos gostavam de apanhar pancada"). A diferença dos "humores" de ambos os contos se deve, então, à função desejada pelos autores para a leitura de seus textos. Machado propõe a denúncia do que é amplamente conhecido, mas que permanece, ainda assim, encoberto e dissimulado; Turguêniev expõe um vislumbre de uma realidade negada a fim de projetar um futuro imaginado.

Central para a ideia de aproximação dos contextos culturais e sociais russo e brasileiro, o avanço capitalista em meados do século XIX se reflete em Pai contra mãe e Khor e Kalínitch sobretudo através da pressão econômica sobre a subsistência de Candinho e sua família, no conto machadiano, e a liberdade parcial conquistada por Khor através da prosperidade financeira, em Turguêniev. A relação com o sistema ascendente é antitética nas duas histórias. Candinho é um indivíduo livre e empobrecido do meio urbano, que conta com uma mínima educação formal (sabe ler), não tem vínculo de nenhuma natureza a não ser afetivo (sua família) e econômico (os empregos aos quais se dedica). Khor e Kalínitch são legalmente dependentes de seu senhor, vivem no ambiente rural, e sua condição servil é reforçada ou atenuada pelo mérito próprio: o 
primeiro comercia bens de consumo, desfruta de relações privilegiadas com seu superior e é economicamente autossuficiente, mesmo sendo analfabeto; já o segundo se mantém conformado e dócil e não age para alterar seu lugar social.

No caso do conto machadiano, o capitalismo é ao mesmo tempo causa e efeito da situação de Candinho. Livre, mas empobrecido, tem a existência social sempre ameaçada. O sistema capitalista avança sobre o antigo regime escravocrata e, nessa progressão violenta, empurra parcelas da população para as margens econômicas. Candinho precisa lançar mão de expedientes inseguros (e, num contexto mais amplo, anacrônicos) para sua sobrevivência. O ofício de apanhador de escravos fugidos atualiza a função do capitão-do-mato, capataz responsável pelo controle dos escravos nas grandes unidades produtivas sob o Antigo Regime. O capitalismo - que, numa sequência de encadeamentos de longa duração, defasa pouco a pouco o escravismo joga atores sociais como Candinho para as margens, condiciona seu modo de vida e, ao mesmo tempo, o atrai de volta à viabilidade econômica através de um rearranjo entre os dois sistemas, o pujante e o moribundo. O capitalismo é uma força econômica centrípeta, mas é também centrífuga. A índole pessoal de Candinho (sua inconsequência de não se fixar em nenhum ofício digno) o leva ao limiar da existência social; as relações capitalistas o empurram $e$ puxam-no de volta, contemporaneamente.

Em Turguêniev, o capitalismo aparece desfocado ao fundo como uma promessa de redenção para a qual a abolição da servidão é requisito. Em Khor e Kalínitch há dois embates sociais: o primeiro é a oposição senhores-mujiques (Polutíkin-Khor e Kalínitch), uma relação vertical de dominação calcada na tradição; o segundo é a diferenciação entre os dois camponeses que não é apenas de índole pessoal, mas de inserção econômica, no qual a prosperidade de Khor contrasta com o comodismo e a preservação dos antigos laços de dominação que mantêm Kalínitch em seu lugar na hierarquia social. Aqui, as relações sociais modernas (capitalistas) oferecem aos personagens um cenário novo, diferente do habitual, e potencial vetor de libertação Turguêniev faz com que seja, mais uma vez, a índole pessoal a definir a escolha pela ruptura ou não. O imobilismo social próprio do regime de servidão é minado pelo avanço das relações capitalistas. $\mathrm{O}$ acordo entre Khor e seu patrão (a dispensa do trabalho obrigatório perante um tributo estabelecido pelo nobre) o diferencia da massa de servos (não é mais um simples subjugado como Kalínitch), e o comércio produz as condições para a própria quebra da relação servil. Turguêniev parece propor com isso um novo paradigma em que a mediação social não seja mais feita pelos antigos laços 
tradicionais. A substituição de sistemas sócio-econômicos defasados (o escravismo e o de servidão) por relações modernas capitalistas marca presença como condicionamento da existência e motor das atitudes e escolhas dos personagens.

\section{Conclusão}

Ao traçar um paralelo entre duas peças literárias de contextos marginais do capitalismo no século XIX, procurei destacar a potencialidade de uma análise que considere as especificidades estilísticas no tratamento de sistemas sócio-econômicoculturais - aqui, o escravocrata brasileiro e o servil russo. Meu intuito foi o de fundamentar (ainda que parcialmente e em extensão muito limitada) um embasamento crítico à leitura de Moretti de Brasil e Rússia como malformações nacionais no contexto do capitalismo ascendente. Enquanto "países retardatários", as nações de Machado e Turguêniev produziram uma literatura onde essa condição por vezes se expressa em termos artísticos. $\mathrm{O}$ artigo visou exemplificar essa premissa discutindo seus sistemas socioeconômicos através de dois de seus melhores escritores, estudando suas codificações. Pai contra mãe e Khor e Kalínitch, bem como toda a obra de Machado de Assis e Ivan Turguêniev, oferecem elementos de análise literária aptos, acredito, a um cruzamento com os estudos históricos mais arrojados.

\section{Referências}

ASSIS, Machado de. 50 contos de Machado de Assis. Seleção, introdução e notas por John Gledson. São Paulo: Companhia das Letras, 2007.

BERNARDINI, Aurora Fornoni. Aulas de literatura russa: de Púchkin a Gorestein. São Paulo: Kalinka, 2018.

BIANCHI, M. F. Os últimos dos moicanos [posfácio]. In: TURGUÊNIEV, I. Rúdin. Trad. Fátima Bianchi. São Paulo: Editora 34, 2012. p. 187-200.

CANDIDO, A. Literatura e sociedade: estudos de teoria e história literária. 11. ed. Rio de Janeiro: Ouro sobre Azul, 2010.

FRANK, J. Pelo prisma russo: ensaios sobre literatura e cultura. São Paulo: Edusp, 1992

MORETTI, F. O burguês: entre a história e a literatura. São Paulo: Três Estrelas, 2014. 
SCHWARZ, R. Um mestre na periferia do capitalismo: Machado de Assis. 5. ed. São Paulo: Editora 34, 2012.

TURGUÊNIEV, I. Memórias de um caçador. Tradução Irineu Franco Perpétuo. São Paulo: Editora 34, 2013.

\section{Bibliografia adicional}

ANDERSON, P. Linhagens do Estado absolutista. 3. ed. São Paulo: Brasiliense, 1995.

BERMAN, M. Tudo que é sólido desmancha no ar: a aventura da modernidade. São Paulo: Companhia das Letras, 1987.

CHALHOUB, S. Machado de Assis: historiador. São Paulo: Companhia das Letras, 2003.

GOMIDE, B. B. Dostoiévski na rua do Ouvidor: a literatura russa e o Estado Novo. São Paulo: Edusp, 2018.

MORAES, R. F. Pai contra mãe: a permanência da escravidão nos contos de Machado de Assis. In: Encontro Escravidão e Liberdade, 4., 2009, Curitiba. Disponível em: $<$ http://www.escravidaoeliberdade.com.br/site/images/Textos4/renatamoraes.pdf $>$. Acesso em 5 mar. 2020.

MORETTI, F. Atlas do romance europeu: 1800-1900. São Paulo: Boitempo Editorial, 2003.

SUNDKVIST, L. Turgenev and the question of the Russian artist. Tese (Doutorado em Filosofia) - Sidney Sussex College, University of Cambridge, Cambridge, 2010. Disponível em: <https://www.repository.cam.ac.uk/bitstream/handle/1810/228706/Turgenev_thesis.pdf ? sequence $=1 \&$ isAllowed $=y>$. Acesso em: 15 mar. 2018. 